\title{
Preparation of hydroxyl group containing bridged organosilica membranes for water desalination
}

Kazuki Yamamoto $^{1}$, Joji Ohshita $^{1 *}$, Tomonobu Mizumo ${ }^{1}$, Masakoto Kanezashi ${ }^{2}$, Toshinori Tsuru ${ }^{2 *}$

1 Department of Applied Chemistry, Graduate School of Engineering, Hiroshima University, Higashi-Hiroshima 739-8527, Japan

${ }^{2}$ Department of Chemical Engineering, Graduate School of Engineering, Hiroshima University, Higashi-Hiroshima 739-8527, Japan

Corresponding author: jo@hiroshima-u.ac.jp

\begin{abstract}
Organosilica membranes were prepared by homo- and copolymerization of hydroxymethyl(triethoxy)silane (HMTES) for the first time, and applied to reverse osmosis (RO) to investigate the effects of the hydroxymethyl group. Fourier transform infrared (FT-IR) spectrometry, thermogravimetric analysis (TGA), and water contact angle measurements of the membrane surface indicated that the $\mathrm{C}-\mathrm{OH}$ group of HMTES underwent a condensation reaction with $\mathrm{Si}-\mathrm{OH}$ to form an $\mathrm{Si}-\mathrm{O}-\mathrm{C}$ bond during the calcination at $300{ }^{\circ} \mathrm{C}$.Upon $\mathrm{RO}$ experiments usingan $\mathrm{NaCl}$ aqueous solution, the HMTES membrane exhibited a significant increase of the liquid permeance and a decrease of the $\mathrm{NaCl}$ rejection during the measurement, which arose from the hydrolytic cleavage of the Si-O-C bond to form $\mathrm{Si}-\mathrm{OH}$ and $\mathrm{C}-\mathrm{OH}$ groups upon contact with water. On the other hand, for a membrane derived from the copolymerization of HMTES and bis(triethoxysilyl)ethane (BTESE) in the weight ratio of $1: 1$, liquid permeance was increased gradually to reach a steady state of $3.4 \times 10^{-13} \mathrm{~m}^{3} /\left(\mathrm{m}^{2} \cdot \mathrm{s} \cdot \mathrm{Pa}\right)$, and $\mathrm{NaCl}$ rejection was maintained at a
\end{abstract}


value as high as $95.5 \%$. Thermal stability and chlorine resistance of the membranes were also studied.

Keywords:organosilica membrane, water separation; sol-gel process; hydroxyl group

\section{Introduction}

Polymer and ceramicmembranes for gas and liquid separation have seen a surge in popularity $[1,2]$. Reverse osmosis (RO) membranes have been applied to simple desalination processes that involve the removal of salt from brackish or sea water, and are recognized as one of the most efficient tools to solve the water shortage problem [3-5]. Studies on RO membranes have focused on achieving higher water flux and salt ( $\mathrm{NaCl}$ etc.) rejection since the 1960s. Currently, thin films of aromatic polyamide are widely used as RO membranes because of their high water flux $\left(>0.1 \mathrm{~m}^{3} / \mathrm{m}^{2} \cdot \mathrm{d}\right)$ and salt rejection ( $>99 \%$ ) [6-8].However, the amide linkage is labile to chlorine, which is often employed to prevent biofouling of the membrane surface. In addition, the polyamide membranes must be used at temperatures lower than $45^{\circ} \mathrm{C}$ due to the low thermal stability. To resolve those issues, various alternative materials, such as organic polymers including cellulose acetates $[9,10]$ and modified polyamides [11,12], zeolites [13,14], silicates $[15,16]$, and their composite membranes $[17,18]$, have been studied.

Polysilsesquioxanes (PSQs), which can be readily synthesized by hydrolysis and polycondensation, the so-called sol-gel process of trialkoxysilanes, have been extensively studied as organic-inorganic hybrid materials $[19,20]$. The inorganic Si-O-Si framework in those materials gives rise to the high thermal stability and structural rigidity of the materials. At the same time, the structure of organic bridge is responsible for the materials' flexibility and processability. PSQs have been also studied as RO materials [21-25]. Recently, bridged PSQ membranes prepared by 
the sol-gel process of organically bridged trialkoxysilanes, $\left[\left(\mathrm{R}^{\prime} \mathrm{O}\right)_{3} \mathrm{SiRSi}(\mathrm{OR})_{3}\right]$, have been reported as promising precursors of robust separation membranes. The bridged PSQ membranes usually show high permeability compared to silica or non-bridged PSQ membranes, because the organic bridges expand the siloxane network as a "spacer" to enhance porosity [21-26]. Previously, we reported that silica materials prepared from bis(triethoxysilyl)ethane (BTESE) could be used as robust RO membranes because of their high chlorine tolerance and thermal stabilityup to $90{ }^{\circ} \mathrm{C}$ $[23,24]$. However, the liquid permeability is much lower than that of commercially available polyamide membranes. In our efforts to improve the water permeability, we found that the introduction of ethenylene and ethynylene units in place of the ethylene bridge increased the water permeability by increasing the rigidity and polarity of the bridges $[21,22]$. The rigidity expands the siloxane network to provide even higher porosity, while the higher polarity leads to the better water affinity of the membrane.

In this study, hydroxymethyl(triethoxy)silane (HMTES in Chart 1), which is readily available from a commercial source, was employed as a new silica membrane precursor, in hopes that the high hydrophilicity of the hydroxymethyl group would lead to even higher water permeability. The sol-gel process of HMTES alone or HMTES/BTESE mixtures provided the corresponding membranes that showed separation properties. Unlike Si-OH bonds that readily undergo dehydro coupling to form thermally stable Si-O-Si bonds almost irreversibly under the sol-gel conditions, $\mathrm{C}-\mathrm{OH}$ groups react with $\mathrm{Si}-\mathrm{OH}$ to give less stable $\mathrm{C}-\mathrm{O}-\mathrm{Si}$ linkages in equilibrium. Therefore, it is required to monitor the behavior of the $\mathrm{C}-\mathrm{OH}$ groups carefullyduring the curing process for membrane preparation and $\mathrm{RO}$ experiments with an aqueous $\mathrm{NaCl}$ solution. Interestingly, the C-O-Si bonds were hydrolysed by contact with the aqueous solution to increase the hydrophilicity of the membranes. For mixed membranes of HMTES/BTESE, the present process improved the water permeability without supressing the $\mathrm{NaCl}$ rejection. Usually, silica membranes that are prepared by calcination of silica sol-coated films are rather hydrophobic. The results clearly indicate that the 
post-treatment of HMTES-containing membranes with water offers a new convenient method to increase the hydrophilicity of the silica membranes.Although homo- and copolymerization of HMTES giving the polymer gels have been studied, their utilities as separation membranes and post-hydrolysis of the polymers tuning the hydrophilicity have not yet been reported to our knowledge [27-30].

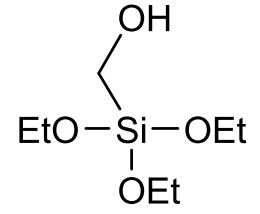

HMTES

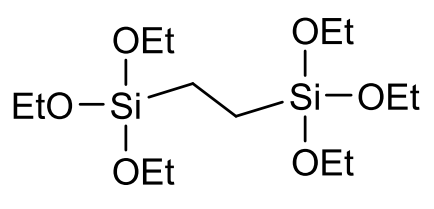

BTESE

Chart 1.Chemical structures of alkoxysilanes investigated in this study.

\section{Experimental}

\subsection{General}

Precursors HMTES (50\% ethanol solution) and BTESE were obtained from Gelest Inc. and used as received. Sol particle sizes were measured in $5 \mathrm{wt} \%$ ethanol solution by means of dynamic light scattering (DLS) on a Malvern Zetasizer Nano (Malvern, ZEN3600) analyzer. Fourier transform

infrared (FT-IR) spectra were measured with a Shimadzu IRAffinity-1 spectrometer using coating films on silicon wafer. Thermogravimetric analysis (TGA) was carried out on a SII EXSTAR TG-DTA6200 thermal analyzer in the temperature range of $100{ }^{\circ} \mathrm{C}$ to $1000{ }^{\circ} \mathrm{C}$ after keeping the sample at $100{ }^{\circ} \mathrm{C}$ for 30 min to remove adsorbed water.Contact angle measurements of water drops on the silica surface were performed with a Kyowa DM300 contact angle meter using coating films on silicon wafer. Solution conductivities were measured using a HORIBA ES-51 conductivity meter. Mechanical strengths of the film surface were examined according to the ASTM Standard D 
3363-92 [31], using a TQC Wolff-Wilborn tester (COTEC) with pencils varying in hardness from $6 \mathrm{~B}$ to $6 \mathrm{H}$.

\subsection{Sol-gel process}

To an ethanol (5 wt $\%$ ) solution of HMTES or HMTES/BTESE(0.25 g) was slowly added an $\mathrm{HCl}$ (aq) as the acidic catalyst in the $\mathrm{HCl} /$ alkoxysilane/ $\mathrm{H}_{2} \mathrm{O}$ molar ratio of $1 / 10 / 900$. The mixture was stirred for $12 \mathrm{~h}$ at room temperature to produce the sol, the size of which was measured by DLS, as presented in Fig. 1. The mixture was then diluted with ethanol to $0.25 \mathrm{wt} \%$ and preserved in a refrigerator until use. A gel powder was obtained by drying the sol at $60{ }^{\circ} \mathrm{C}$ in a glass vial, and a coating film was prepared by drop casting on silicon wafer. Then, the gel powder and the coating film were subjected to TGA, and IR spectrometryand water contact angle measurements, respectively.

A porous-alumina tubular support (NOK Corp.,average pore size $150 \mathrm{~nm}$, outer diameter $3 \mathrm{~mm}$, length $50 \mathrm{~mm}$ ) was coated five times with $\mathrm{TiO}_{2}(\mathrm{ca} .30 \mathrm{~nm}$ average particle size, $0.72 \mathrm{wt} \%$ aqueous solution) and three times with $\mathrm{SiO}_{2}-\mathrm{ZrO}_{2}(\mathrm{Si} / \mathrm{Zr}=1$, ca. $50 \mathrm{~nm}$ average particle size, $0.25 \mathrm{wt} \%$ aqueous solution). After each coating, the tubular support was heated at $550{ }^{\circ} \mathrm{C}$ for 15 min in air. At this stage, the average pore size distribution of the intermediate layer was evaluated to be less than $2 \mathrm{~nm}$ by nanopermporometry [32,33]. The separation layer was prepared by coating the silica sol on the intermediate layer, followed by calcination at $300{ }^{\circ} \mathrm{C}$ in a nitrogen atmosphere.

\subsection{Water permeability measurements}

RO desalination measurements were performed using a $2000 \mathrm{ppm} \mathrm{NaCl}$ aqueous solution at $25{ }^{\circ} \mathrm{C}$. The feed pressure of 1.0 MPa was applied with a plunger pump. Liquid permeance $\left(L_{\mathrm{p}}\right)$ and $\mathrm{NaCl}$ rejection (R)were calculated based on equations (1) and (2), respectively, where $\Delta P$ and $\Delta \pi, J v$, and 
$C_{\mathrm{f}}$ and $C_{\mathrm{p}}$ are, respectively, differences in applied pressure and osmotic pressure, permeate water flux, and $\mathrm{NaCl}$ concentrations of feed and permeate determined from their conductivities.Details of water permeability measurements are available in the literature [28].

$L_{\mathrm{p}}=J_{\mathrm{v}} /(\Delta P-\Delta \pi)$

$R=\left(1-C_{\mathrm{p}} / C_{\mathrm{f}}\right) \times 100$

\subsection{Stability test of BT-HM50 membrane towards chlorine exposure}

The chlorine stability of the membrane was evaluated $10 \% \mathrm{NaClO}$ (Aldrich). A chlorine solution was prepared at $100 \mathrm{ppm}$ and $\mathrm{pH}$ was adjusted to 7 using a $0.2 \mathrm{M} \mathrm{KH}_{2} \mathrm{PO}_{4}$ buffer solution. The membrane was periodically immersed in, and removed from, the chlorine solution, which was placed in a sealed, stirred, dark glass bottle. Their performance was then tested after a thorough rinse with deionized water.

\section{Results and discussion}

\subsection{Preparation of membranes}

The sols were prepared by HCl-catalyzed hydrolysis/polycondensation of HMTES, BTESE, and their mixtures BT-HMx $(x=$ loading ratio of HMTES in wt $\%)$ with water in ethanol. Immediately after the monomers were dissolved in the $\mathrm{HCl}$ (aq)/ethanol solution, the particle sizes were determined by DLS as being 0.6-0.7 $\mathrm{nm}$, while stirring for $12 \mathrm{~h}$ increased the sizes to approximately 2-3 nm (Fig. 1), clearly indicating the progress of polymerization. The sol particle sizes were suitable for coating on the intermediate layer, whose average pore size was less than $2 \mathrm{~nm}$. 


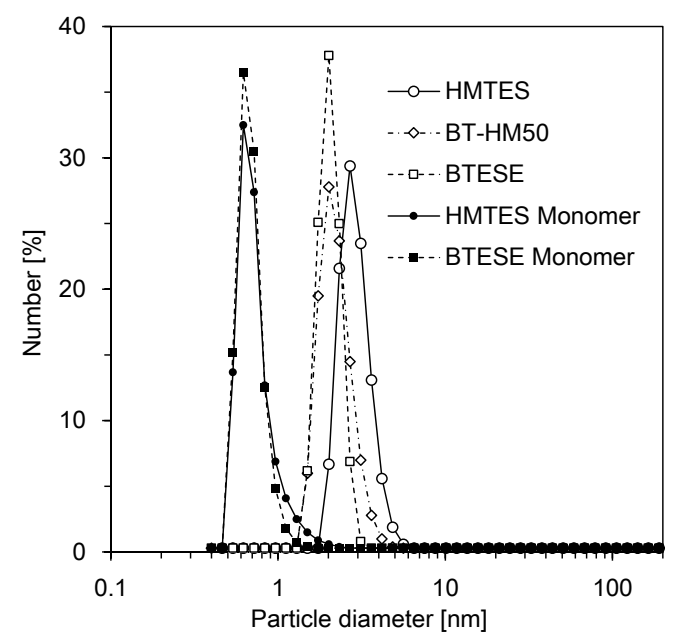

Fig. 1. Size distributions of monomers and sols determined by DLS.

The thermal behavior of the gel powders that were prepared by drying the sol at $60{ }^{\circ} \mathrm{C}$ was investigated to determine the calcination temperature of the membranes. It is known that a higher calcination temperature results in the better separation selectivity by network densification[24,34]. However, treatment of the gel powders at an elevated temperature may cause the degradation of organic units. TG traces of HMTES and BTESE gel powders are shown in Fig. 2. The gel powders were heated at $100{ }^{\circ} \mathrm{C}$ for 30 min under a gentle nitrogen flow to remove adsorbed water before measurements. The weight loss around $100-300{ }^{\circ} \mathrm{C}$ was likely due to the condensation reaction of residual Si-OH groups in the gel powders [35]. For HMTES, the condensation of C-OH and $\mathrm{Si}-\mathrm{OH}$ bonds would be also involved in this temperature range, which might be responsible for the greater weight loss of the HMTES gel [28]. The weight loss around $400-700{ }^{\circ} \mathrm{C}$ seemed to be due to the thermal decomposition of organic groups [35].The larger weight loss of the HMTES gel than that of the BTESE gel in this temperature range was likely due to the different composition of the gels. For example, assuming complete combustion of the wholly condensed gels of HMTES $\left(\mathrm{SiCH}_{2} \mathrm{O}_{2}\right)_{n}$ and BTESE $\left(\mathrm{Si}_{2} \mathrm{C}_{2} \mathrm{H}_{4} \mathrm{O}_{3}\right)_{n}$ in air producing $\left(\mathrm{SiO}_{2}\right)_{n}$ led to the theoretical weight loss of $19 \%$ and $9 \%$, respectively. In nitrogen, SiOC ceramics would be produced [36]. It seemed likely 
that the BTESE gels bearing $\mathrm{C}-\mathrm{C}$ bonds provided the higher content of carbon remaining in the ceramics, thus giving the smaller weight loss. Both of the gels prepared from HMTES and BTESE showed less weight loss in nitrogen than in air. On the basis of these observations, calcination of the coated gels was carried out at $300{ }^{\circ} \mathrm{C}$ under a nitrogen atmosphere (vide infra).

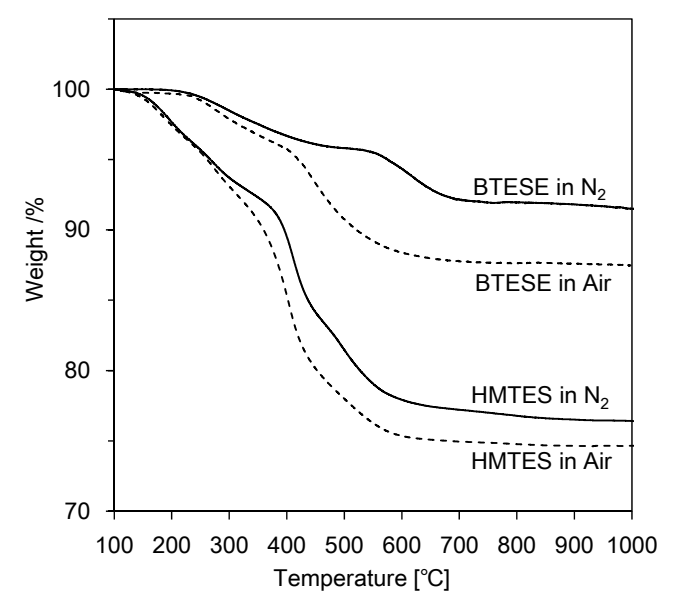

Fig. 2.TG traces of HMTES and BTESE gel powders.

The temperature-dependent FT-IR spectra of aHMTES film coated on a silicon wafer are shown in Fig.3. Measurements were performed by heating the film under a nitrogen flow of $100 \mathrm{~mL} / \mathrm{min}$. Broad absorption bands ascribed to the hydroxyl group around 3000-3700 $\mathrm{cm}^{-1}$ [37] were weakened gradually as the temperature was increased from $100{ }^{\circ} \mathrm{C}$ to $300{ }^{\circ} \mathrm{C}$. Finally, the absorption bands nearly disappeared at $300{ }^{\circ} \mathrm{C}$, indicatingcondensation of Si-OH and $\mathrm{C}-\mathrm{OH}$ bonds. Because the Si-O stretching band of Si-OH atapproximately $910 \mathrm{~cm}^{-1}[37]$ was clearly weakened at $200{ }^{\circ} \mathrm{C}$, the $\mathrm{OH}$ band that remained at temperatures above $200{ }^{\circ} \mathrm{C}$ would be ascribed mainly to the $\mathrm{C}-\mathrm{OH}$ unit originating in HMTES and the Si-OH unit having no surrounding Si-OH bonds to react with. The condensation of $\mathrm{C}-\mathrm{OH}$ and $\mathrm{Si}-\mathrm{OH}$ bonds likely occurred at a temperature higher than $200{ }^{\circ} \mathrm{C}$, forming C-O-Si bonds. Gradual high-frequency shift of the O-H stretching band as elevating the 
operation temperature may be due to the suppressed hydrogen bonding by lowered $\mathrm{OH}$ concentration in the gels.

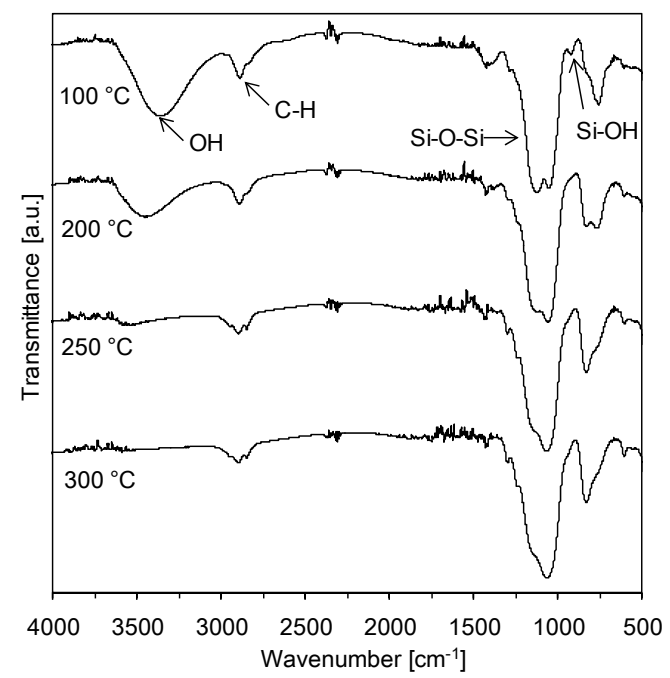

Fig. 3. FT-IR spectra of HMTES film on silicon wafer at different temperatures under nitrogen flow.

Water contact anglemeasurements of the silica film surface were performed to investigate the hydrophilicity of the film, as shown in Fig.4. A smaller contact angle indicates a higher hydrophilicity of the film, and thus higher water permeability would be expected [38]. It is known that the contact angle is affected not only by the chemical structure of the film surface but also other factors including the surface morphology. However, assuming that the film morphology does not significantly changed regardless of the calcination temperature allows to monitor the changes of chemical structure of the surface depending on the temperature by the contact angle of the same film, although comparison between the films would be difficult. Upon calcination at $100{ }^{\circ} \mathrm{C}$, similarcontact angles were obtained for the films of $\operatorname{HMTES}\left(61^{\circ}\right)$ and BTESE $\left(55^{\circ}\right) . \quad$ At $300{ }^{\circ} \mathrm{C}$, the hydrophobicity of HMTES film markedly increased (contact angle $=85^{\circ}$ ), whilethat ofthe BTESE film was not very much changed $\left(66^{\circ}\right)$. This result is in agreement with the disappearance of the $\mathrm{OH}$ absorption band of the HMTES film around $100{ }^{\circ} \mathrm{C}-300{ }^{\circ} \mathrm{Cin}$ the FT-IR spectra. 


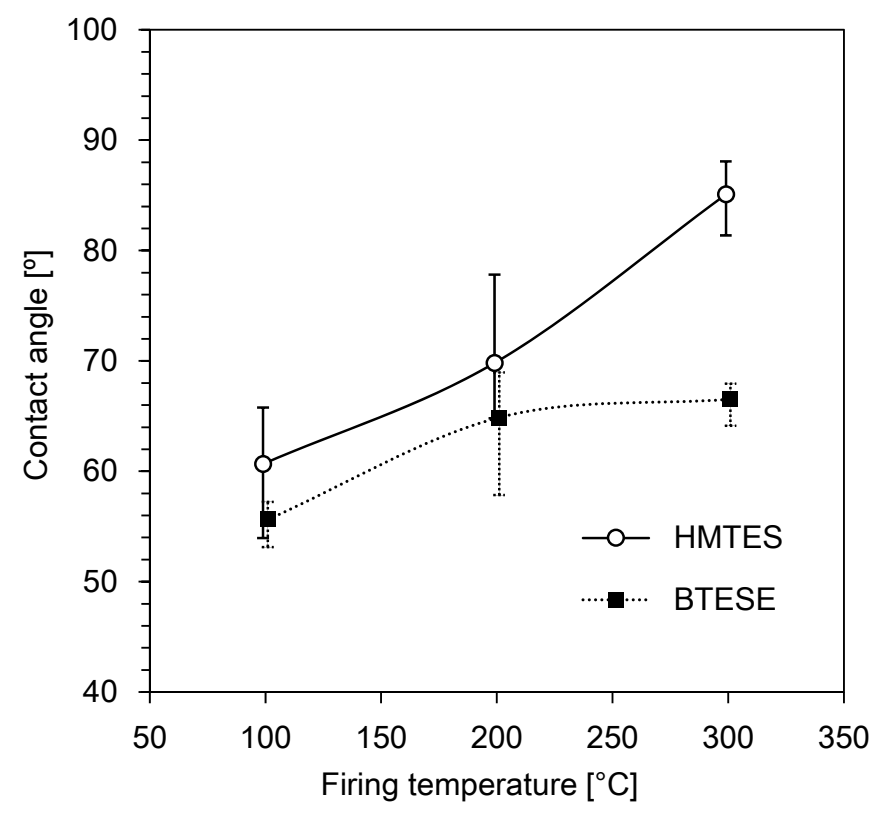

Fig. 4. Water contact angles of HMTES and BTESE films coated on silicon wafer after heating at $100{ }^{\circ} \mathrm{C}$ in air, $200{ }^{\circ} \mathrm{C}$ in $\mathrm{N}_{2}$, and $300{ }^{\circ} \mathrm{C}$ in $\mathrm{N}_{2}$.

Membranes based on HMTES, BTESE, and their mixtures BT-HMx were prepared by casting the sol on inorganic supports (see Experimental section), followed by calcination. Membrane morphology was investigated bycross-sectional SEM. An image of the BT-HM50 membraneis presented in Fig.5. Although the interface between the separation layer based on BT-HM50 and the inorganic intermediate layer cannot be clearly seen, the thickness of the dense layer on the alumina support increased by coating the separation layer and the surface was smoothened. No apparent defects,such ascracks and pinholes were observed for the separation membrane. 


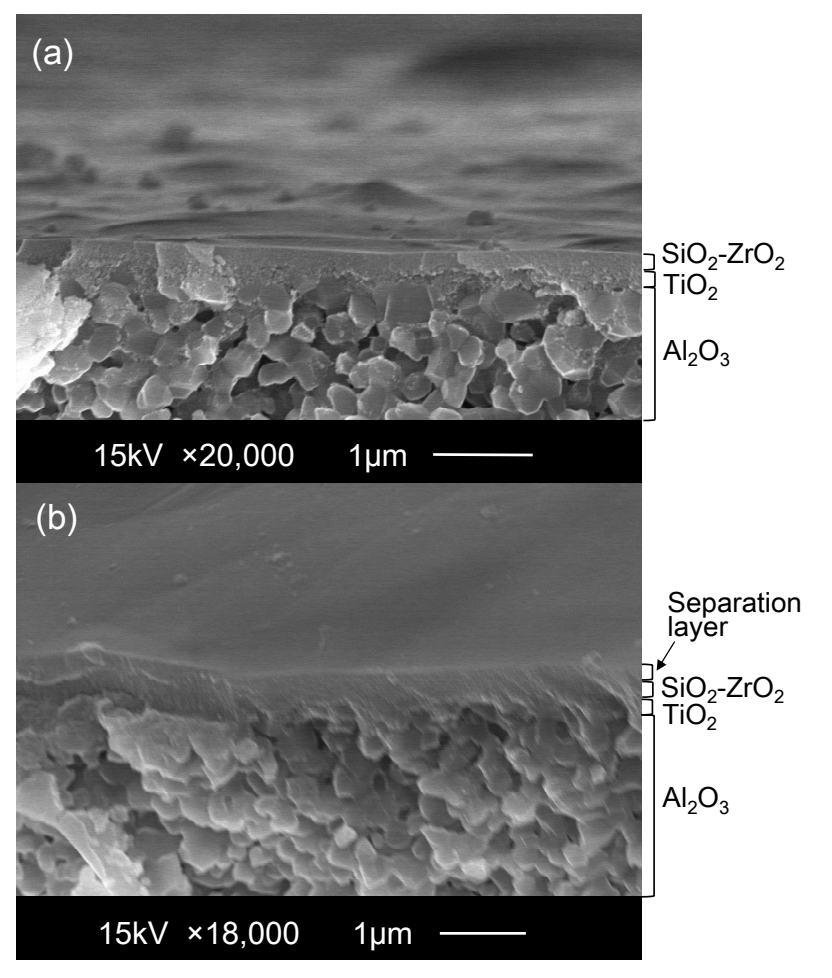

Fig. 5. Cross-sectional SEM image of membrane, (a) before and (b) after coating of separation layer of BT-HM50.

\subsection{RO performance of HMTES-based membranes}

Liquid permeance measurements were performed using a $2000 \mathrm{ppm} \mathrm{NaCl}$ aqueous solution at 1.0 $\mathrm{MPa}$ at $25^{\circ} \mathrm{C}$, as shown in Fig.6, and the data are summarized in Table 1. The liquid permeance and the $\mathrm{NaCl}$ rejection of the BTESE membrane were $3.1 \times 10^{-14} \mathrm{~m}^{3} / \mathrm{m}^{2} \cdot \mathrm{s} \cdot \mathrm{Pa}$ and $95.2 \%$, respectively, reproducing previous data [21-23]. The increase in $\mathrm{NaCl}$ rejection at the early stage of the $\mathrm{RO}$ experiments was presumably due to the electrostatic repulsion arising from the adsorption of $\mathrm{NaCl}$ ions in the membranes. The present HMTES membrane exhibiteda significant increase of the liquid permeance and a decrease of the $\mathrm{NaCl}$ rejection, as compared to those of the BTESE membrane, and the tendency was enhanced on contact with water during the RO measurements. It 
was also observed that the membrane was partly peeled off from the substrate during the measurement. As HMTES-gel was reported to be stable to water and not soluble even in cold sulphuric acid, softening of the membrane by partial hydrolysis seemed to be responsible for the mechanical damage (vide infra) [28]. The mixed membranes BT-HMx were also examined with respect to water desalination. As shown in Fig. 6, the permeancewas increased and the $\mathrm{NaCl}$ rejection was decreased as the incorporation ratio of HMTES (x) was increased. Similar to the HMTES membrane, liquid permeance was increased gradually during the RO experiments, although no mechanical damage of the membrane was observed. On the other hand, the $\mathrm{NaCl}$ rejection was not evidently changed, giving nearly constant values during the measurements, as shown in Fig.6. The best performance was obtained for the BT-HM50 membrane whose liquid permeance and $\mathrm{NaCl}$ rejection were $3.4 \times 10^{-13} \mathrm{~m}^{3} /\left(\mathrm{m}^{2} \cdot \mathrm{s} \cdot \mathrm{Pa}\right)$ and $95.5 \%$, respectively.
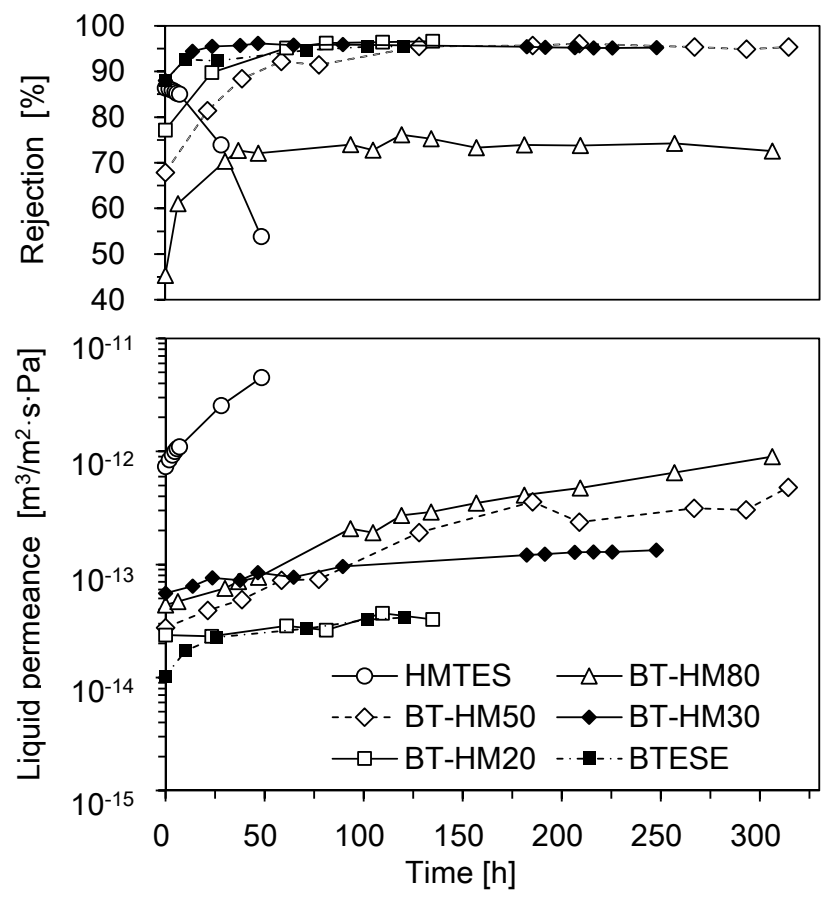

Fig. 6. Plots of liquid permeance and $\mathrm{NaCl}$ rejection of homo- and copolymer membranes of HMTES and BTESE versus operation time of RO experiment with $2000 \mathrm{ppm} \mathrm{NaCl}$ solution.Numbers in the abbreviations indicate thewt $\%$ values of HMTES loaded for 
copolymerization. Error ranges are $26 \%$ and $3 \%$ for liquid permeance and $\mathrm{NaCl}$ rejection, respectively.

Table 1. Summary of RO measurement of membranes

\begin{tabular}{|c|c|c|c|c|c|}
\hline \multirow[t]{2}{*}{ Membrane $^{\mathrm{a}, \mathrm{b})}$} & \multicolumn{2}{|c|}{$\begin{array}{l}\text { Liquid permeance } \\
\qquad\left[\mathrm{m}^{3} /(\mathrm{m} \cdot \mathrm{s} \cdot \mathrm{Pa})\right]\end{array}$} & \multicolumn{2}{|c|}{$\mathrm{NaCl}$ Rejection [\%] } & \multirow{2}{*}{$\begin{array}{l}\text { Required time to be } \\
\text { steady state }[\mathrm{h}]\end{array}$} \\
\hline & $0 \mathrm{~h}$ & Steady state & $0 \mathrm{~h}$ & Steady state & \\
\hline HMTES & $7.3 \times 10^{-13}$ & - & 86.4 & - & $>300$ \\
\hline BT-HM80 & $4.4 \times 10^{-14}$ & - & 45.4 & - & $>300$ \\
\hline BT-HM50 & $2.4 \times 10^{-14}$ & $3.4 \times 10^{-13}$ & 67.8 & 95.5 & 130 \\
\hline ВТ-НM30 & $5.6 \times 10^{-14}$ & $1.2 \times 10^{-13}$ & 88 & 95.3 & 180 \\
\hline BT-HM20 & $2.3 \times 10^{-14}$ & $3.5 \times 10^{-14}$ & 77.1 & 96.1 & 100 \\
\hline BTESE & $1.0 \times 10^{-14}$ & $3.1 \times 10^{-14}$ & 88 & 95.2 & 26 \\
\hline
\end{tabular}

a) Permeance and $\mathrm{NaCl}$ rejection of substrate coated with intermediate layer only: $4.5 \times 10^{-12} \mathrm{~m}^{3} /(\mathrm{m} \cdot \mathrm{s} \cdot \mathrm{Pa}), 12.5 \%$. b) Numbers in the abbreviations indicate the $\mathrm{wt} \%$ values of HMTES loaded for copolymerization.

The plausible polymer network structures are presented in Fig.7. Upon calcination at $300{ }^{\circ} \mathrm{C}$, most of the Si-OH and C-OH groups underwent condensation to form Si-O-Si and Si-O-C linkages, thus providing dense network structures. Alkoxy-Si (Si-OC) bonds are usually less stable towards hydrolysis than disiloxane ( $\mathrm{Si}-\mathrm{OSi}$ ) bonds, and hydrolysis of the Si-OC bonds of the polymer network would occur to regenerate $\mathrm{Si}-\mathrm{OH}$ and $\mathrm{C}-\mathrm{OH}$ groups during the $\mathrm{RO}$ experiments, leading to the enhanced water permeability. One might consider the possibility of cleavage of C-OSi bonds, which would also give $\mathrm{Si}-\mathrm{H}$ and $\mathrm{C}-\mathrm{OH}$ groups. However, lower electronegativity of $\mathrm{Si}$ and more spacy bonding around Si than those of $\mathrm{C}$ prefer the nucleophilic attack of water on Si. This would 
reduce the mechanical strength of the HMTES membrane, resulting in membrane peeling in part. However, the Si-O-Si linkages are resistant to hydrolysis. For the mixed membranes, only a limited number of $\mathrm{C}-\mathrm{OH}$ units were introduced and the Si-O-Si bonds that were involved in the membranes to higher extents were not hydrolysed, retaining dense network of the membranes. This makes it possible to utilize the membranes as water-stable separation membranes with relatively high liquid permeance and $\mathrm{NaCl}$ rejection.

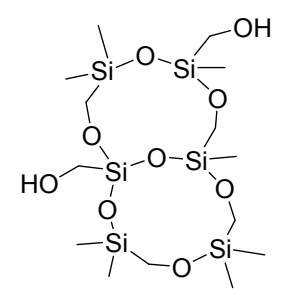

HMTES

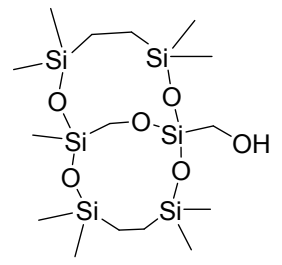

BT-HM50

Immersion in water $\downarrow$ Hydrolysis

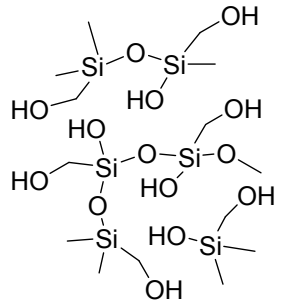

HMTES

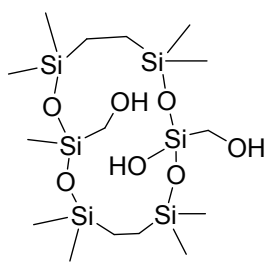

BT-HM50

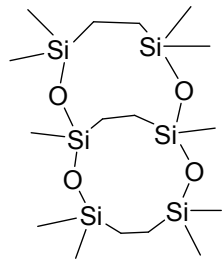

BTESE

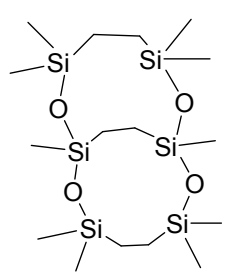

BTESE

Fig.7.Plausible network structures of HMTES- and BTESE-based membranes before and after immersion in water.

To investigate the mechanical strength, we carried out the pencil hardness tests of some of the present membranes. The pencil hardness was $>6 \mathrm{H}$ for the BTESE membrane and $\mathrm{H}$ for the BT-HM50- and HMTES membranes. The pencil hardness of the membranes decreased by soaking experiments as being 5H, F, and HB for BTESE-, BT-HM50-, and HMTES membranes, respectively, indicating higher mechanical strength for the BT-HM50membrane than that of the HMTES membrane. 
To investigate the behavior of the Si-O-C bonds of HMTES-based membranes during the RO experiments, water soaking experiments were conducted for the BTESE and HMTES membranes. BTESE and HMTES sols were casted on silicon wafers, and the resulting sol films were dried at 100 ${ }^{\circ} \mathrm{C}$ for $30 \mathrm{~min}$. The FT-IR spectra of the as prepared films are presented in Fig. 8 a-1 and b-1 for BTESE and HMTES, respectively, which reveal O-H and Si-OH stretching bands around 3400 and $910 \mathrm{~cm}^{-1}$. On heating the films at $300{ }^{\circ} \mathrm{C}$ for $30 \mathrm{~min}$ in nitrogen, which are the same conditions as those for the calcination (Fig. 8, a-2 and b-2), those bands were weakened, indicating that dehydrolytic condensation had taken place. When the HMTES film was immersed in water for 12 $\mathrm{h}$ and then dried at $100{ }^{\circ} \mathrm{C}$ for $30 \mathrm{~min}$, the $\mathrm{O}-\mathrm{H}$ and $\mathrm{Si}-\mathrm{OH}$ bands were again intensified to intensities that were approximately half the original ones (Fig. 8, b-1 and b-3). The process could be repeated (Fig. 8, b-4 and b-5), but the intensities of the bands after the second soaking treatment were approximately one-third of the original ones (b-5). In contrast to the HMTES film, the BTESE film showed no obvious changes in the repetitive heating/soaking process (Fig. 8, a-3, a-4, and a-5). The results indicate that only the hydrolysis of the Si-OC bonds occurred when the films were soaked, and the Si-O-Si bonds remained unchanged. The reason for the irreversibility of this process of the HMTES membrane is still unclear. 

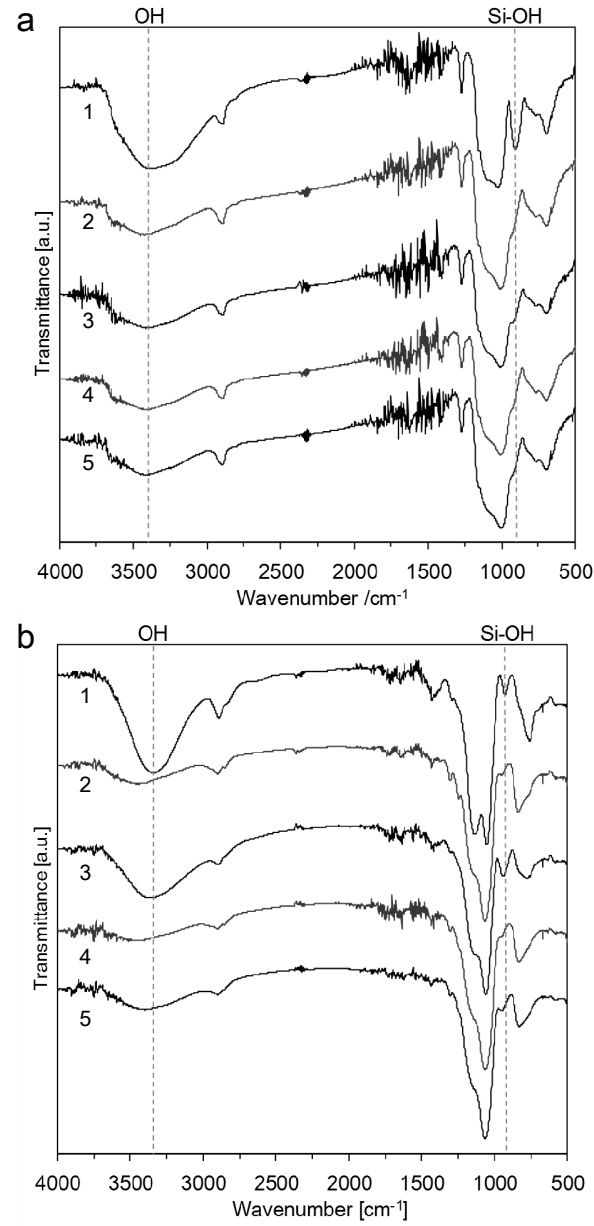

Fig. 8. FT-IR spectra of BTESE (a) and HMTES (b) films on silicon wafer upon repetitive soaking in water and calcination at $300{ }^{\circ} \mathrm{C}$.

To know more about the stability of the membranes, we carried out an accelerated RO experiment of the BT-MH50 membrane (Fig.9). Thus, the membrane that had been subjected to the RO experiment at $25^{\circ} \mathrm{C}$ for $320 \mathrm{~h}$ (Fig. 9) was further treated at $60^{\circ} \mathrm{C}$. The performance of the membrane reached a steady state after $20 \mathrm{~h}$ with a permeance and an $\mathrm{NaCl}$ rejection of approximately $3 \times 10^{-12} \mathrm{~m}^{3} / \mathrm{m}^{2} \cdot \mathrm{s} \cdot \mathrm{Pa}$ and $92 \%$, respectively. Cooling down to $25{ }^{\circ} \mathrm{C}$ resulted in the decreased permeance and $\mathrm{NaCl}$ rejection, but they remained still at good levels of $2 \times 10^{-12}$ 
$\mathrm{m}^{3} / \mathrm{m}^{2} \cdot \mathrm{s} \cdot \mathrm{Pa}$ and $86 \%$, respectively. No peeling the membrane from the substrate was observed.

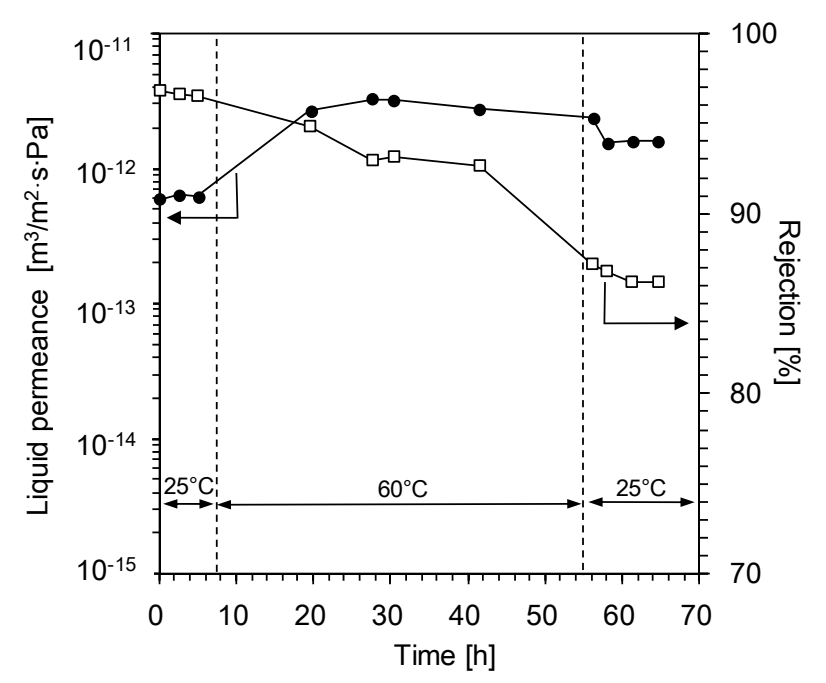

Fig. 9. Plots of liquid permeance and $\mathrm{NaCl}$ rejection of BT-HM50 membranes versus operation time of RO experiment with $2000 \mathrm{ppm} \mathrm{NaCl}$ solution at 25-60 ${ }^{\circ} \mathrm{C}$.Before this experiment, the membrane had been subjected to the RO experiment at $25{ }^{\circ} \mathrm{C}$ for $320 \mathrm{~h}$. Error ranges are $26 \%$ and $3 \%$ for the liquid permeance and the $\mathrm{NaCl}$ rejection, respectively.

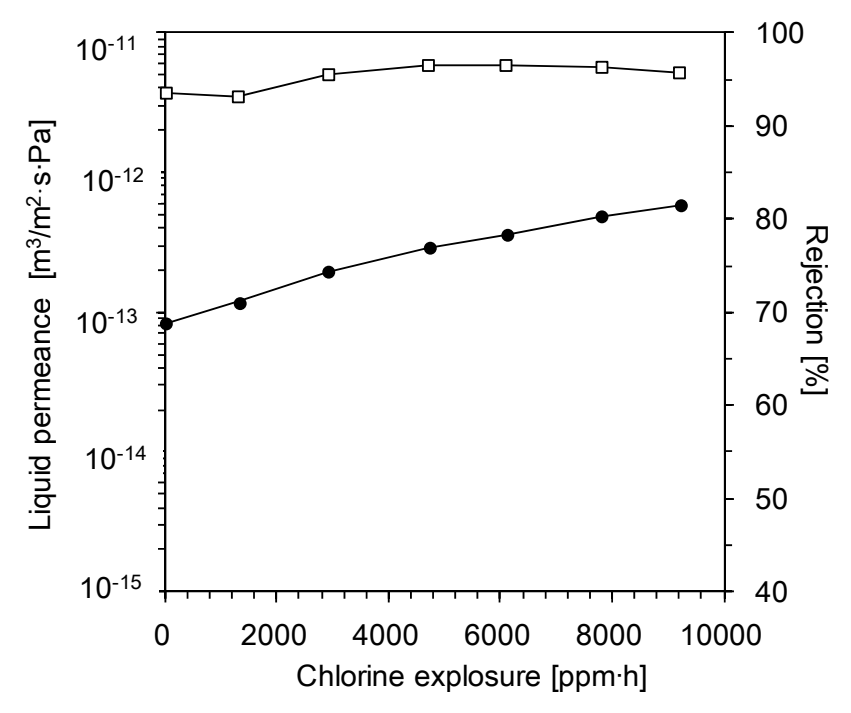


Fig. 10. Effects of chlorine exposure on NaClrejection and water permeability of BT-HM50-membrane using $100 \mathrm{ppm} \mathrm{NaClO}$ solution. Error ranges are $26 \%$ and $3 \%$ for the liquid permeance and the $\mathrm{NaCl}$ rejection, respectively.

Stability of the BT-HM50 membrane towards chlorine was also examined. As expected, no evident effects of chlorine on the RO performance were observed up to exposure of $9600 \mathrm{ppm} \cdot \mathrm{h}$ (Fig. 10), although continuous increase of liquid permeance was observed likely due to the hydrolysis of Si-O-C bonds, as observed for the simple RO experiments using NaClaq (vide supra).

\section{Conclusions}

New bridged silica membranes were prepared via sol-gel polymerization using HMTES as the precursor. The hydroxyl groups on carbon $(\mathrm{C}-\mathrm{OH})$ of the HMTES membrane underwent condensation with $\mathrm{Si}-\mathrm{OH}$ groups at a temperature above $200{ }^{\circ} \mathrm{C}$, generating the $\mathrm{Si}-\mathrm{O}-\mathrm{C}$ linkage. In RO measurements, immersing the membrane in water caused hydrolysis of the Si-O-C groups to regenerate $\mathrm{C}-\mathrm{OH}$ and $\mathrm{Si}-\mathrm{OH}$ groups. The formation of $\mathrm{OH}$ groups increased the liquid permeance but decreased the $\mathrm{NaCl}$ rejection at the same time to suppress the separation properties of the membrane. Detachment of the membrane from the substrate was also observed during the measurement. To improve membrane stability, we prepared mixed membranes by copolymerization of BTESE and HMTES. The mixed membranes showed sufficient stability. Although liquid permeability was increased gradually during the RO measurement, no significant decrease of the $\mathrm{NaCl}$ rejection was observed. Finally, a membrane with good liquid permeance of $3.4 \times 10^{-13} \mathrm{~m}^{3} /\left(\mathrm{m}^{2} \cdot \mathrm{s} \cdot \mathrm{Pa}\right)$ and high $\mathrm{NaCl}$ rejection of $95.5 \%$ was obtained. The permeability of the

membrane was not as high as that of commercial polyamide membranes $\left(10^{-11} \mathrm{~m}^{3} /\left(\mathrm{m}^{2} \cdot \mathrm{s} \cdot \mathrm{Pa}\right)\right)$. However, this procedure provides a new opportunity to improve the performance of water separation 
of silica based membranes. One might consider that possible changes in permeability of the HMTES-containing membranes during the RO process cause difficulties upon their practical applications. However, the membranes may reach a stable states by a soaking procedure as described above prior to the use for RO. The BT-HM50 membrane exhibited further increase of the permeance at $60{ }^{\circ} \mathrm{C}$. At the same time, however, the $\mathrm{NaCl}$ rejection decreased. Although it still remained at a good level, the membrane stability may be improved by employing cross-linking comonomers and/or tuning the monomer ratio, if necessary.

By the use of the present procedure involving the sol-gel process of HMTES/BTESE and post-hydrolysis, the hydrophilicity of membranes seems to be readily controlled, by changing the soaking time and the content of HMTES in the membranes, thus providing membranes with desired hydrophilicity. Studies to apply this procedure to other silica materials are now underway.

\section{Acknowledgements}

This research was supported by the project "Development of Robust RO/NF Membranes for Various Types of Water Resources" of the Core Research for Evolutional Science and Technology, Japan Science and Technology Agency (CREST, JST).

\section{References}

[1] Z. Dong, G. Liu, S. Liu, Z. Liu, W. Jin, J. Membr. Sci. 450 (2014) 38-47.

[2] M. Carta, R. Malpass-Evans, M. Croad, Y. Rogan, J. C. Jansen,P. Bernardo, F. Bazzarelli, N. B. McKeown,Science 339(2013) 303-307.

[3] K. P. Lee, T. C. Arnot, D. Mattia, J. Membr. Sci. 370(2011) 1-22.

[4] D. Li, H. Wang, J. Mater. Chem. 20 (2010) 4551-4566.

[5] C. Fritzmann, J. Löwenberg, T. Wintgens, T. Melin, Desalination 216(2007) 1-76. 
[6] T. A. Saleh, V. K. Gupta, Separ. Purif. Tech.89 (2012) 245-251.

[7] J. Glater, S. K. Hong, M. Elimelech, Desalination 98 (1994) 325-345.

[8] T. Shintani, H. Matsuyama, N. Kurata, Desalination 207 (2007) 340-348.

[9] S. Waheed, A. Ahmad, S. M. Khan, S. Gul, T. Jamil, A. Islam, T. Hussain, Desalination351 (2014) 59-69.

[10] S. Yu, Q. Cheng, C. Huang, J. Liu, X. Peng, M. Liu, C. Gao, J. Membr. Sci. 434 (2013) 44-54.

[11] C. K. Kim, J. H. Kim, I. J. Roh, J. J. Kim, J. Membr. Sci. 165 (2000) 189-199.

[12] S. Belfer, Y. Purinson, O. Kedem, ActaPolym. 49 (1998) 574-582.

[13] L. Li, J. Dong, T. M. Nenoff, R. Lee, J. Membr. Sci. 243 (2004) 401-404.

[14] I. Kumakiri, T. Yamaguchi, S. Nakao, J. Chem. Eng. Jpn.33 (2000) 333-336.

[15] S. Wijaya, M. C. Duke, J. C. Diniz da Costa, Desalination 236 (2009) 291-298.

[16] C. X. C. Lin, L. P. Ding, S. Smar, J. C. Diniz da Costa, J. Colloid Interface Sci. 368 (2012) $70-76$.

[17] J. Duan, E. Litwiller, I. Pinnau, J. Membr. Sci. 473 (2015) 157-164.

[18] H. Zhao, S. Qiu, L. Wu, L. Zhang, H. Chen, C. Gao, J. Membr. Sci. 450 (2014) 249-256.

[19] P. Kidsaneepoiboon, S. P. Wanichwecharungruang, T. Chooppawa, R. Deephum, T. Panyathanmaporn, J. Mater. Chem. 21 (2011) 7922-7930.

[20]Y. Kaneko, H. Toyodome, T. Mizumo, K. Shikinaka, N. Iyi, Chem. Eur. J. 20 (2014) 9394-9399.

[21] R. Xu, M. Kanezashi, T. Yoshioka, T. Okuda, J. Ohshita, T. Tsuru, ACS Appl. Mater. Interfaces 5 (2013) 6147-6154. 
[22] R. Xu, S. M. Ibrahim, M. Kanezashi, T. Yoshioka, K. Ito, J. Ohshita, T. Tsuru, ACS Appl. Mater. Interfaces 6 (2014) 9357-9364.

[23] R. Xu, J. Wang, M. Kanezashi, T. Yoshioka, T. Tsuru, Langmuir 27 (2011) 13996-13999.

[24] S. M. Ibrahim, R. Xu, H. Nagasawa, A. Naka, J. Ohshita, T. Yoshioka, M. Kanezashi, T. Tsuru, RSC Adv. 4 (2014) 23759-23769.

[25] Y. T. Chua, C. X. C. Lin, F. Kleitz, X. S. Zhao, S. Smart, Chem. Commun. 49 (2013) 4534-4536.

[26] H. L. Castricum, G. G. Paradis, M. C. Mittelmeijer-Hazeleger, R. Kreiter, J. F. Vente, J. E.ten Elshof, Adv. Funct. Mater. 21 (2011) 2319-2329.

[27] N. G. Poulos, J. R. Hall, M. C. Leopold, Langmuir 31 (2015) 1547-1555.

[28] B. Arkles, K. King, K. Pannell, Silicon 5 (2013) 187-197.

[29] W. Kudo, M. Takahashi, K. Okamoto, S. Kimura, H. Miyata, Langmuir 29 (2013) 8193-8196.

[30] H. Du, P. D. Hamilton, M. A. Railly, A. B. d'Avignon, P. Biswas, N. Ravi, J. Colloid Interface Sci. 340 (2009) 201-208.

[31] The American Society for Testing and Materials (ASTM) D 3363-92, Test Method for Film Hardness by Pencil Test.

[32] T. Tsuru, T. Hino, T. Yoshioka, M. Asaeda, J. Membr. Sci. 186 (2001) 257-265.

[33] T. Tsuru, Y. Takata, H. Kondo, F. Hirano, T. Yoshioka, M. Asaeda, Sepr. Purif. Technol. 32 (2003) 23-27.

[34] H. Nagasawa, T. Niimi, M. Kanezashi, T. Yoshioka, T. Tsuru, AIChE J. 60 (2014) 4199-4210.

[35]M. Kanezashi, M. Kawano, T. Yoshioka, T. Tsuru, Ind. Eng.Chem. Res., 51(2012) 944-953.

[36] K. Yamamoto, J. Ohshita, T. Mizumo, T. Tsuru, J. Non-Cryst. Solid. 408 (2015) 137-141. 
[37] Y. X. Pang, S. N. B. Hodgson, B. Weglinski and D. Gaworska, J. Mater. Sci., 41 (2006) $5926-5936$.

[38] H. I. Kim, S. S. Kim, J. Membr. Sci. 286 (2006) 193-201.

\section{Graphical Abstract}

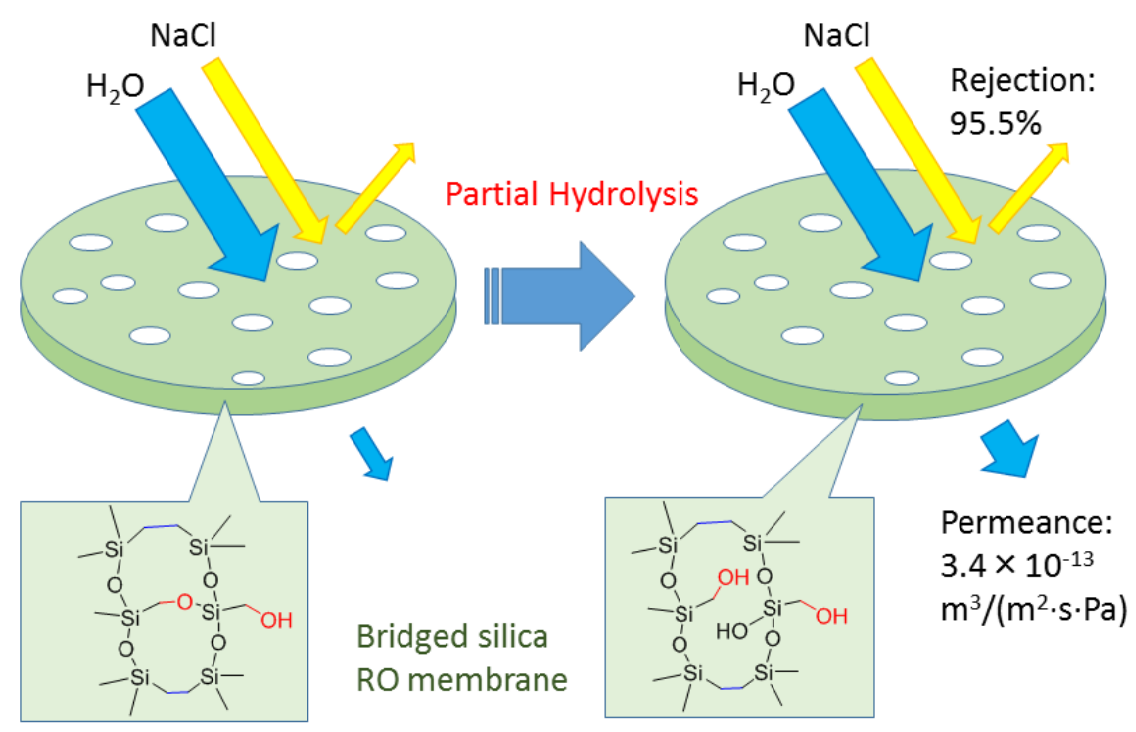

